\title{
A CERÂMICA POPULAR BAIANA: suas origens e principais influências
}

\section{The Bahia's Popular Ceramics: it's origins and main influences}

Celso Almeida; Mestrando em Artes Visuais na Linha de Pesquisa Arte \& Design: Teoria, Crítica e História; PPGAV/EBA - Universidade Federal da Bahia - UFBA.

Professor da Escola de Engenharia da Universidade Católica do Salvador - UCSAL.

n4hellz@gmail.com | celsoalmeida@me.com

\section{Resumo}

Este trabalho busca evidenciar o desenvolvimento da Cerâmica Popular Baiana durante os séculos até chegar ao seu estágio atual. Dos primeiros habitantes de nossa terra, os indígenas, e suas bonecas, urnas e utensílios de barro queimados em fogueiras; à chegada do colonizador europeu com sua influência na técnica, nos equipamentos, na forma e na decoração; culminando no povo negro, com seu amor pelas suas entidades expressado num amor de mesma medida pelo barro, pela terra. Da efervescência deste caldeirão cultural, formador de nossa identidade, vêm a nossa cerâmica atual, arte digna e profundamente representativa de nosso povo baiano e brasileiro.

Palavras-chave: Cerâmica, Artesanato, Herança, Tradição, Cultura.

\begin{abstract}
This paper seeks to show the development of the Bahia's Popular Ceramics during the centuries, until reaching its current stage. The first inhabitants of our land, indigenous, and their dolls, urns and clay utensil, burned at the stake; the arrival of European settlers with their influence on technique, equipment, form and decoration; culminating in the black people, with their love expressed in equal measure by the clay and the earth. The effervescence of this cultural melting pot, forming our identity, came to our current ceramics, art worthy and deeply representative of our people of Bahia and Brazil.
\end{abstract}

Keywords: Ceramics, Handicraft, Heritage, Tradition, Culture. 


\title{
Uma introdução temática
}

\begin{abstract}
Deem a um pedreiro - escreve H. Spencer - tijolos bem cozidos, duros, de arestas vivas, e ele poderá construir sem argamassa uma parede bastante sólida, de grande altura. Se, pelo contrário, os tijolos são feitos de má argila, se a sua cozedura foi irregular, se são toscos, fendidos, quebrados, ser-lhe-á impossível sem argamassa construir uma parede igual à primeira em altura e estabilidade. (SPENCER, s/d)
\end{abstract}

O lido com a cerâmica - um dos mais antigos ofícios da história humana -, surgiu a partir da transformação das propriedades físicas e químicas da massa argilosa, de modo a suprir algumas das nossas mais básicas necessidades: transportar e armazenar água, preparar alimentos, honrar os mortos e os deuses, ou simplesmente para libertar nossas fantasias e o nosso imaginário, saindo assim do ramo utilitário e entrando no lúdico, com brinquedos e miniaturas de coisas que nos cercavam e talvez ainda nos cerquem. A cerâmica é universal. Está presente nas origens de praticamente todas as culturas. Vasos Canopos egípcios ${ }^{1}$, urnas funerárias indígenas, estatuetas précolombianas, o Exército de Terracota do Imperador Qin ${ }^{2}$ na China, todos estes são exemplos do quanto a cerâmica faz parte da história da humanidade.

Sobre o barro na arte popular brasileira, Clotilde de Carvalho Machado disse:

\begin{abstract}
"sua maior representação são as pequenas figuras, os tipos populares, pequenos incidentes, ou fatos do nosso dia-a-dia. São frágeis na sua estrutura, mas de uma enorme força artística que admiramos pela sua ingenuidade e, sobretudo, pela maneira com que são elaboradas: por pessoas sem nenhuma escola de arte e que, no entanto, sabem dosar suas figuras com tal encantamento, chegando quase a Ihes dar vida, doçura, timidez e audácia" (1977, p. 17).
\end{abstract}

Este testemunho, apesar de abordar somente a produção de cerâmica figurativa e/ou lúdica no artesanato popular brasileiro, expressa a maneira como esta arte é enraizada em nossa cultura.

Através deste artigo, vamos identificar e começar a traçar um paralelo entre os primórdios da cerâmica baiana, suas origens pré-coloniais, as influências ibérica, indígena e negra, e a cerâmica popular baiana na atualidade. Ao fazer isto, espero poder lançar luz à importância da preservação da cerâmica popular e tradicional como uma forma pura de percepção artística, como bem disse Marlice Almeida (1994), “A necessidade de criar é inerente ao homem. Ela germina naturalmente e não pode ser detida. O que o homem cria com as mãos, expressando a sua vida, o seu imaginário, é a forma mais primordial da arte, a necessidade do agir/ser".

\footnotetext{
${ }^{1}$ Vasos canópicos ou canopos eram recipientes utilizados no Antigo Egito para colocar órgãos retirados do morto durante o processo de mumificação, visando assegurar uma vida no Além.

${ }^{2}$ Exército de terracota, Guerreiros de Xian ou ainda Exército do imperador Qin, é uma coleção de mais de oito mil figuras de guerreiros e cavalos em terracota, em tamanho natural, encontradas próximas do mausoléu do primeiro imperador da China
} 


\section{A cerâmica baiana pré-colonial}

A Bahia é, dentre os estados Brasileiros, um dos que se têm mais claras noções sobre sua pré-história ${ }^{3}$. Organizados como sociedades de horticultores e caçadorescoletores, os índios que habitavam o território baiano no período pré-colonial, já trabalhavam com diversos materiais, dentre eles a pedra e a cerâmica, que são os achados arqueológicos que mais resistiram às intempéries ao longo dos séculos.

Dentre as maneiras de catalogar e analisar as diferentes produções cerâmicas pré-coloniais, definindo a que cultura pertenceram, destacam-se a observação da matéria-prima, das técnicas de manufatura das peças, do estilo da queima e da forma como tratavam a superfície.

O material, a argila, é um composto inorgânico, formado principalmente por silicatos de alumínio onde, geralmente, também há a presença de ferro, magnésio, sódio, potássio e cálcio. É justamente a incidência e a intensidade da presença destes materiais na composição da argila que tornam possível a identificação da sua fonte de extração. Outro elemento que também pode ser um fator diferencial na identificação de uma produção cerâmica específica é o uso de determinados antiplásticos ${ }^{4}$. No caso dos antiplásticos naturais da cerâmica pré-colonial baiana, podemos citar alguns de origem petrológica, como o quartzo, a mica, areias e feldspatos. Em algumas tradições cerâmicas indígenas, como na fase Jurubeba da Tradição Tupiguarani ${ }^{5}$, na Chapada Diamantina, há principalmente o uso de cacos de cerâmica triturados - o conhecido chamote - como um antiplástico intencional.

Antes dos portugueses introduzirem o torno cerâmico, as populações indígenas que habitavam o nosso território usavam-se de duas técnicas principais para a construção do corpo da peça cerâmica: o acordelamento e a modelagem. O uso de uma ou de outra variava de acordo com o a serventia da peça depois de pronta. No caso do acordelamento, ou roletado, ele consistia basicamente na superposição de cilindros feitos de argila, formando anéis espiralados. Geralmente utilizada na produção de peças que precisam ser "levantadas", a técnica do roletado é ainda hoje usada em diversas comunidades cerâmicas tradicionais, principalmente para a construção de potes e moringas (Figura 1). Já a modelagem, por sua vez, consiste na confecção de uma peça a partir de um bloco inteiro de argila, manipulado até tomar a forma de estatuetas, cachimbos, dentre outros.

\footnotetext{
${ }^{3}$ OTT, Carlos. Pré-História da Bahia. Salvador, Progresso, 1958, p. 37.

${ }^{4}$ Antiplástico: também conhecido como desengordurante ou tempero, é o elemento que equilibra a plasticidade da argila, podendo ser intencional ou natural.

${ }^{5}$ Tradições e fases: termos utilizados para designar unidades culturais baseadas fundamentalmente em registros cerâmicos e líticos, considerando-se certos traços diacríticos que se repetem por um tempo num determinado espaço. (ETCHEVARNE, Carlos. Cerâmica Popular, Salvador: 1994. p. 31: Acerca das primeiras manifestações ceramistas da Bahia).
} 


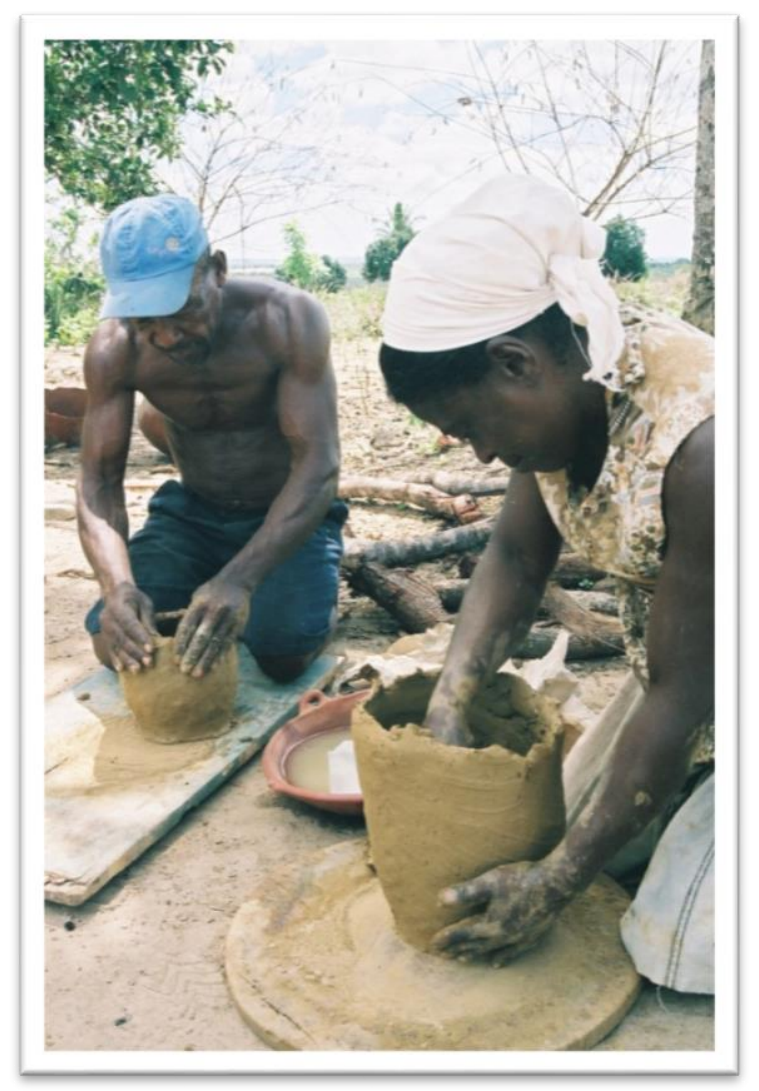

Figura 1 - "Irará. "Suspensão" ou “levantamento" da peça. Técnica do roletado"

AUTOR: Arquivo Instituto de Artesanato Visconde de Mauá - SETRE/GOV. da Bahia

No que se refere ao processo de queima, há ai a necessidade de certo domínio da fonte calorífica, visto que, para o sucesso da empreitada, estão componentes como o tipo e a qualidade dos combustíveis empregados, o tempo de exposição, o teto de temperatura e o tipo de atmosfera, influindo, assim, no formato do forno e do processo da queima. Como não havia ainda a existência de fornos cerâmicos como conhecemos hoje até a chegada dos portugueses, os povos pré-coloniais (aqui referidos também como indígenas) utilizavam-se principalmente de poços - que lhes davam a vantagem de aumentar o potencial calórico dos combustíveis utilizados - e fogueiras (Figuras 3, 4, 5 e 6).

No âmbito do tratamento da superfície, ou acabamento visível, a cerâmica pode ser lisa - alisada - artifício usado para eliminar o aspecto rugoso e áspero, assim diminuindo a porosidade e tornando a superfície mais impermeável; ou pode ser também decorada, imprimindo assim motivos que demonstrem traços culturais, estéticos, religiosos ou de desenvolvimento técnico (domínio da técnica) do grupo. 


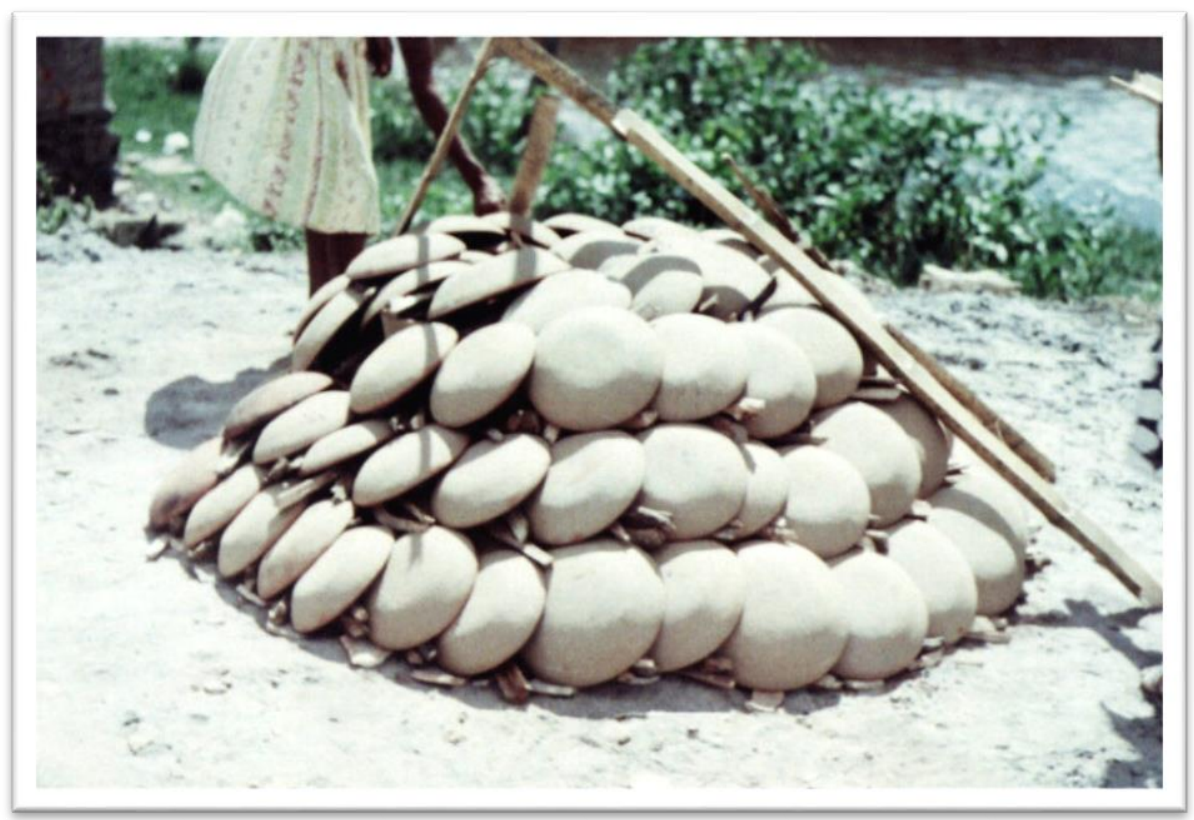

Fig. 3 - "Coqueiros. Empilhamento de peças para o processo de queima".

AUTOR: Arquivo Instituto de Artesanato Visconde de Mauá - SETRE/GOV. da Bahia

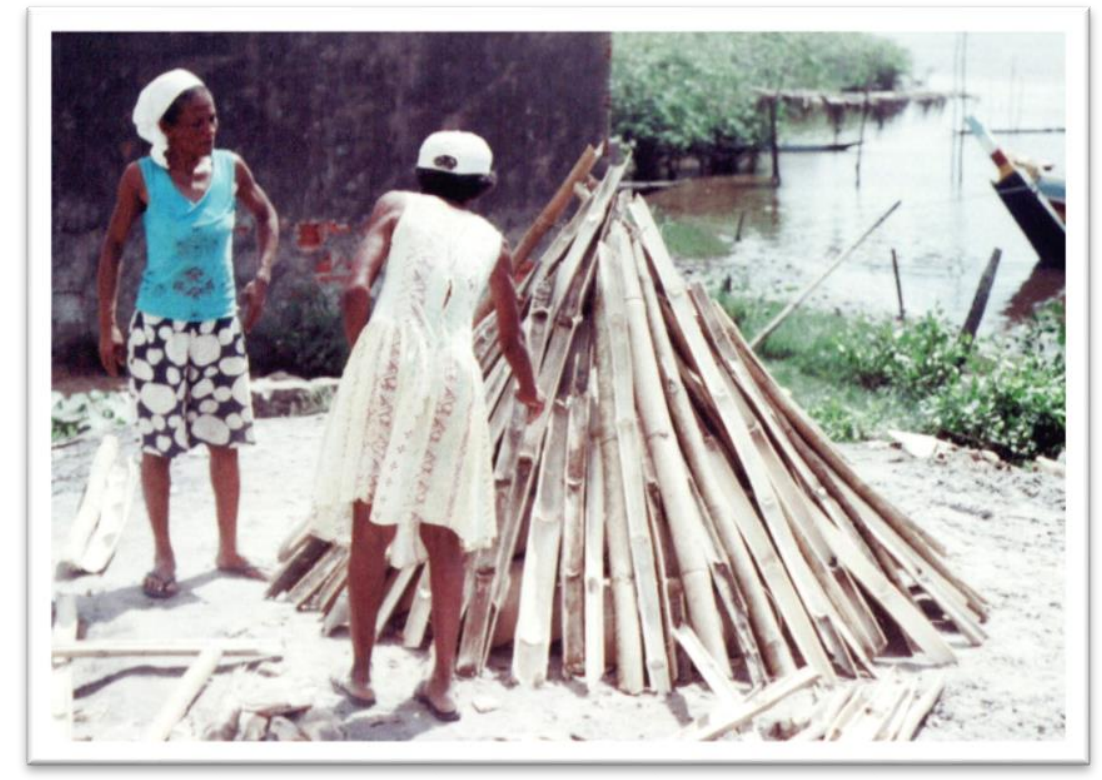

Fig. 4 - "Coqueiros. Montagem da fogueira para queima da produção".

AUTOR: Leandro. Arquivo Instituto de Artesanato Visconde de Mauá - SETRE/GOV. da Bahia 


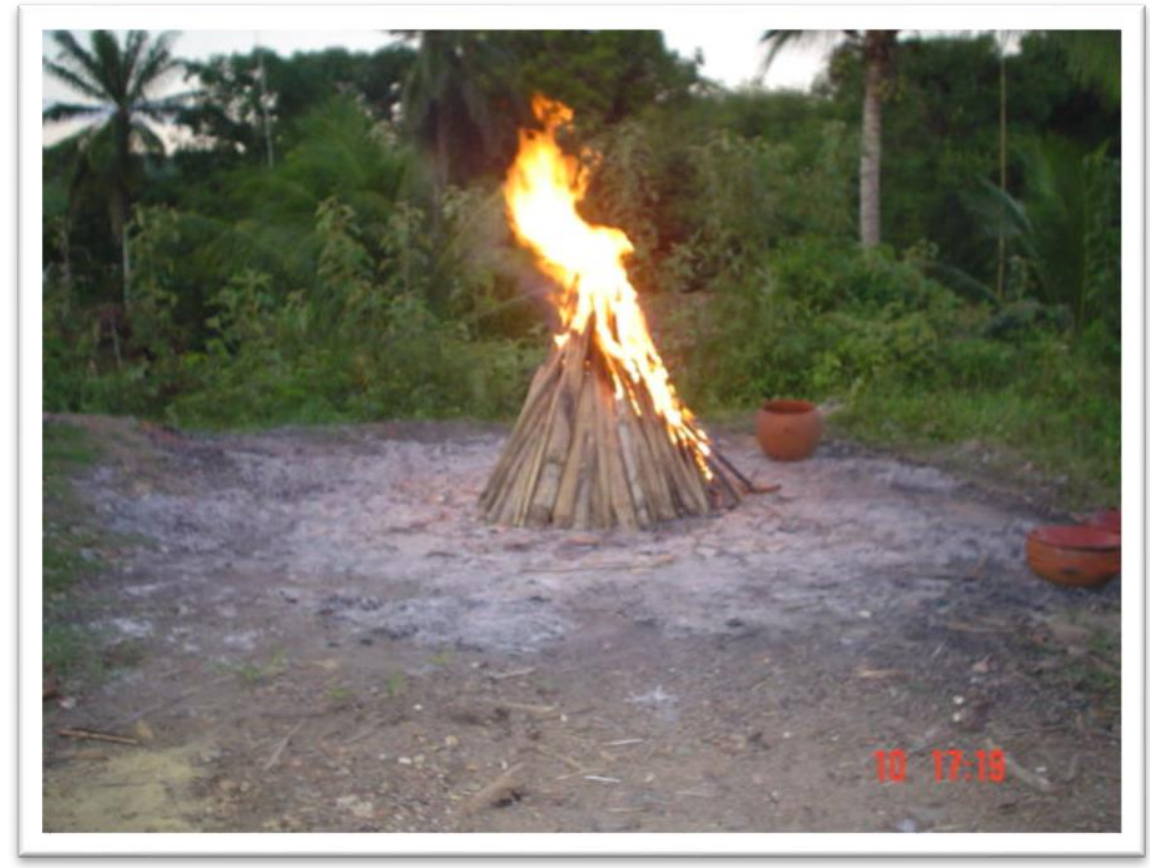

Fig. 5 - "Coqueiros - Início da queima”.

AUTOR: Leandro. Arquivo Instituto de Artesanato Visconde de Mauá - SETRE/GOV. da Bahia

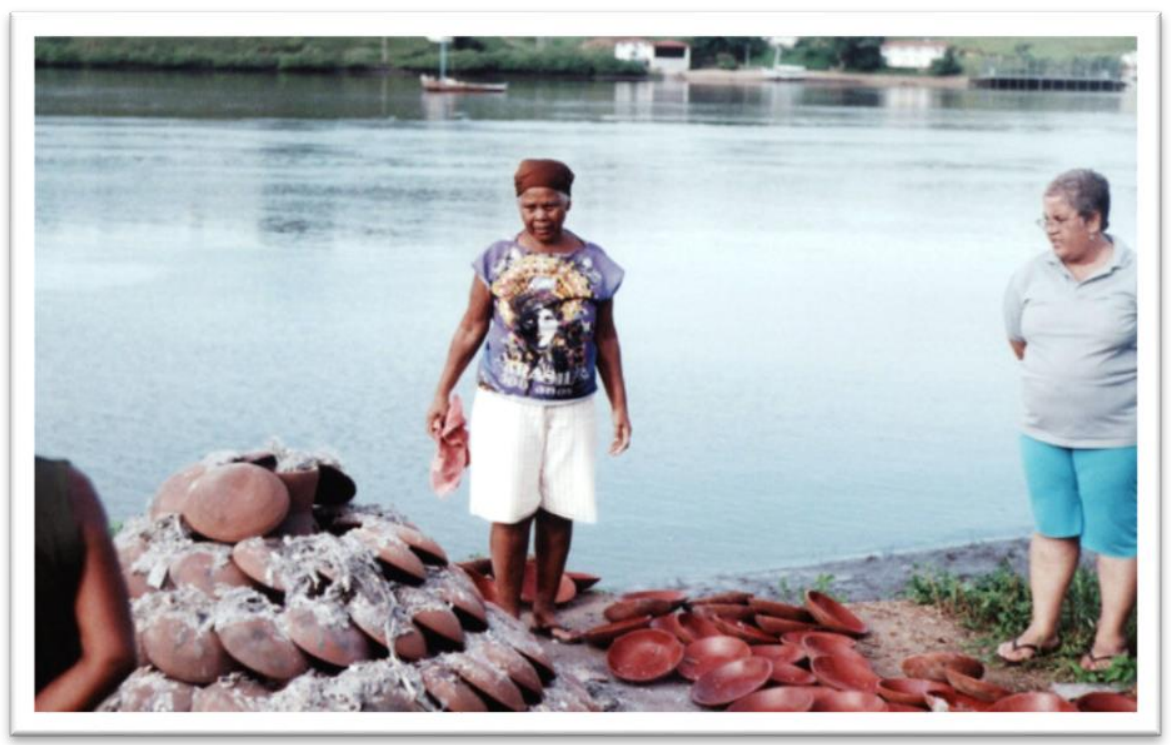

Fig. 6 - "Coqueiros. Retirada das peças após a queima”.

AUTOR: Leandro. Arquivo Instituto de Artesanato Visconde de Mauá - SETRE/GOV. da Bahia

Existem diversos casos de ambos os tratamentos de superfície ocorrer na mesma peça, como na cerâmica de Rio Real (Figuras 7 e 8). Por esta razão, a decoração é tomada como elemento diagnóstico de identidade cultural (ETCHEVARNE, 1994). 


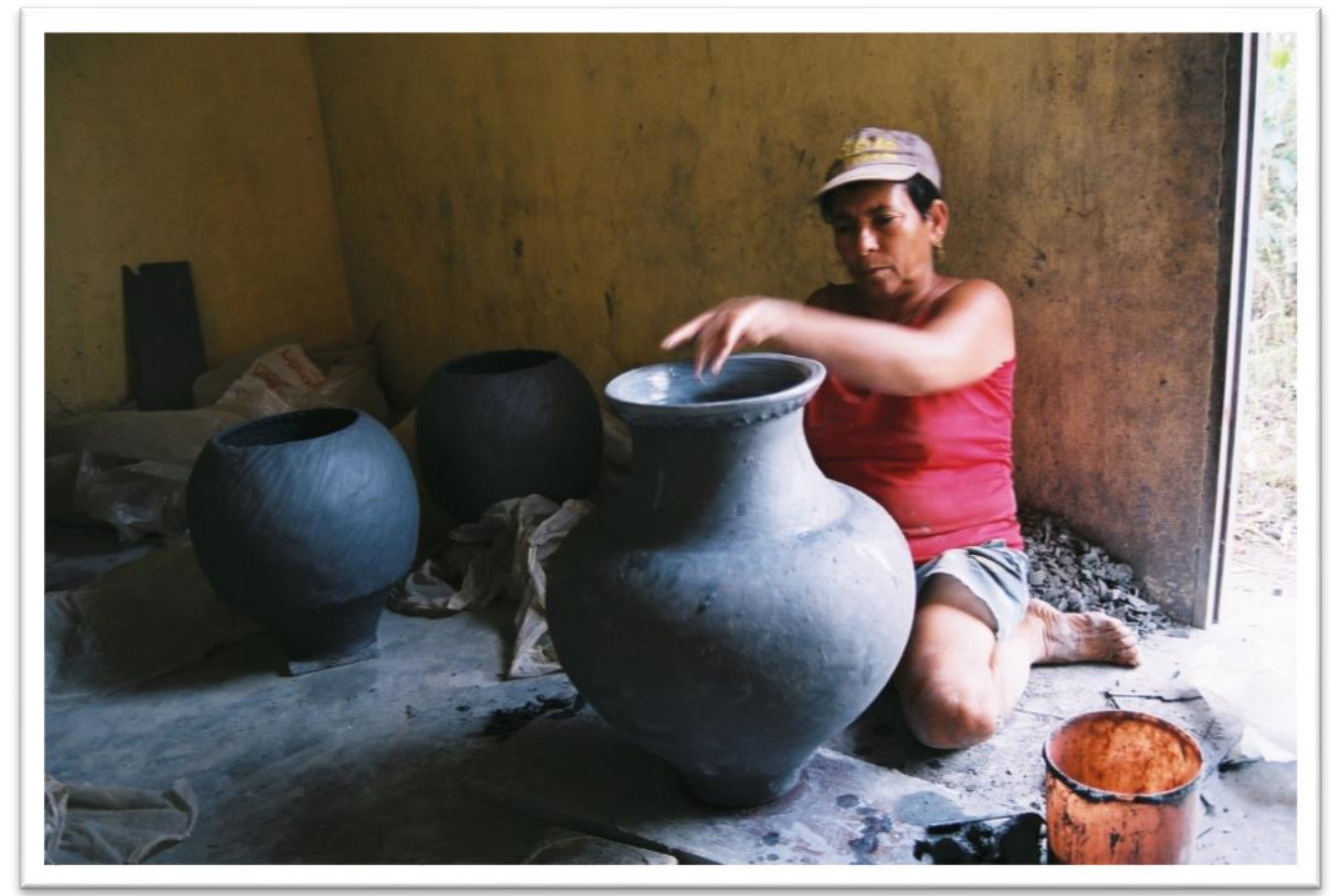

Fig. 7 - "Rio Real. Alisamento da peça".

AUTOR: Leandro. Arquivo Instituto de Artesanato Visconde de Mauá - SETRE/GOV. da Bahia

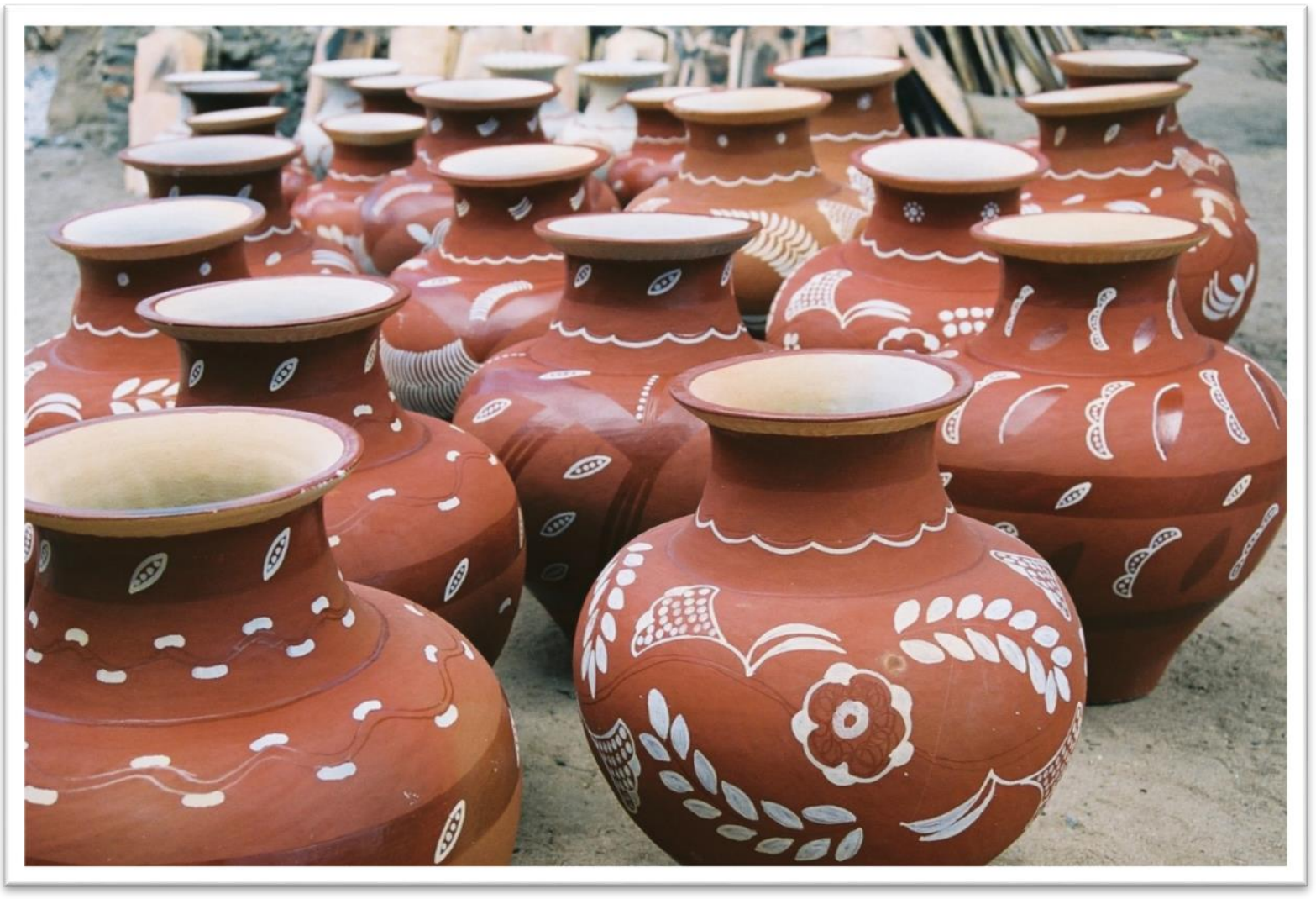

Fig. 8 - "Rio Real. Conjunto de potes prontos e decorados".

AUTOR: Leandro. Arquivo Instituto de Artesanato Visconde de Mauá - SETRE/GOV. da Bahia 
Dentre as culturas ceramistas indígenas na Bahia, temos dois grupos principais, denominados Tradição Aratu e Tradição Tupiguarani.

Na cerâmica Aratu, as urnas funerárias são a peça chave de sua distinção. Variava pouco suas formas de acordo com o ambiente, geralmente possuíam superfície lisa, porém podiam sim, eventualmente, receber tratamento decorativo próximo à abertura. Com relação ao tamanho, a variação era de acordo com o tamanho do indivíduo a ser enterrado. No ramo utilitário, há a predominância de panelas e tigelas, bem como as urnas funerárias. São geralmente sem decoração, exceto por uma característica que distingue esta Tradição das outras culturas ceramistas da Bahia: a presença de ondulações nas bordas de alguns vasilhames.

A tradição Tupiguarani, por sua vez, está dividida em subtradições de acordo com os elementos decorativos que as diferenciam, como a subtradição pintada, a corrugada e a escovada. Deixando de lado o aspecto decorativo, há também outro elemento de suma importância na cerâmica da Tradição Tupiguarani, que é o formato particular de determinados vasilhames que, segundo ETCHEVARNE:

\footnotetext{
"apresentam figuras compostas, com ombros e pescoço acentuados e um setor carenado que serve de nexo entre duas formas, separando a parte superior da inferior. Este tipo de morfologia repete-se em diferentes tamanhos e proporções, em concordância com a sua funcionalidade. Assim, tanto urnas funerárias como panelas e potes podem refletir essa preferência compositiva dos corpos cerâmicos" (1994, p. 40).
}

Quando se fala na identificação dos grupos anteriores à colonização, a produção cerâmica toma um papel principal, pois permite identificar culturas e seus modos de vida cotidianos de acordo com os utensílios cerâmicos que fabricavam, quer seja para os ritos fúnebres, quer para armazenagem e preparação dos seus alimentos. Esta análise nos permite mapear não só a incidência bem como a propagação destes povos e de suas culturas em todo o território nacional, expandindo-se além das fronteiras do estado da Bahia. Com a chegada do português colonizador, a influência Ibérica toma conta da nossa produção cerâmica, mas não sem ser também atingida diretamente pelas técnicas que já existiam até então, como o roletado no levantar da peça e a decoração com corantes argilosos como a tabatinga (tupi tawa'tinga: argila mole, com certo teor de matéria orgânica, encontrada nas cores amarela e branca) e o tauá (tupi ta'wa: argila que contém óxido de ferro, queimada, adquire coloração vermelha).

\section{A influência lbérica e a louça de santo negra}

Apesar de mantidas diversas características do fazer cerâmico indígena e précolonial, após a chegada dos portugueses, vindos da Península Ibérica e, por sua vez, influenciados pelos mouros e civilizações mediterrâneas, a produção cerâmica baiana tomou novos rumos. Adquiriu características influenciadas por este branco colonizador, como o uso do torno, a vidragem, além do uso de fornos cobertos, em formato de capela ou abóbada, e não mais a buracos no chão e fogueiras, como era a queima pré-colonial. 
Foram as primeiras construções que criaram a demanda por artesãos oleiros europeus. Estes Mestres Oleiros, por sua vez, repassaram à população não só a arte de fazer telhas e tijolos, mas também um modelo estético que, senão copiado, era pelo menos uma estilização dos modelos tradicionais do velho continente. Em alguns momentos, o prestígio que essas louças adquiriram permitiu dourações e a exportação para a metrópole ${ }^{6}$.

No âmbito do tratamento decorativo, a pintura com arabescos, flores e espirais é, da mesma maneira que os motivos geométricos para a cerâmica indígena, o indicativo da influência ibérica na peça. Em alguns raros exemplares, predominantemente na região de Maragogipinho, há também a presença de pintura à óleo em algumas peças, sem um manuseio muito elaborado das cores, o artesão preocupa-se apenas em representar pictoricamente o ambiente ao seu redor, o rio, o céu, as árvores e as casas. Este tipo de decoração - a óleo - é um exemplar raro, hoje em dia presente apenas em coleções particulares de arte popular.

O povo negro, talvez por estar - até finais do século XIX - preso ao trabalho escravo, teve uma influência limitada na formação da nossa cerâmica. Sua contribuição principal se dá na chamada Louça de Santo, ou Louça de Deus, que são elementos como talhas, porrões, alguidares, ibás, quartinhas e quartiões que são utilizados em oferendas aos orixás (Nação Ketu), voduns (Nação Gêge) e inquices (Nação Angola). Estas louças servem também para armazenar os banhos de folha, nos assentamentos e confirmações de santos, e na cerimônia do axexé7

As louças de santo são influenciadas não só por elementos estéticos e culturais, mas principalmente pelos religiosos, como as preferências de determinadas divindades por uma ou outra louça, e até mesmo as suas quizilas ${ }^{8}$ e fundamentos. São basicamente peças utilitárias - que exercem um papel primordial durante as celebrações referentes aos Santos da Terra - mas há também a presença de peças de caráter figurativo, representações das divindades do candomblé ou do sincretismo religioso, da mesma maneira como os santos católicos também são representados em cerâmica.

6 PEREIRA, Carlos José da Costa, A cerâmica popular da Bahia apud Cerâmica Popular, Salvador, Instituto Mauá, 1994, p. 19.

\footnotetext{
${ }^{7}$ Axexé ou Axexê é uma cerimônia realizada após o ritual fúnebre (enterro) de uma pessoa iniciada no candomblé.

${ }^{8}$ Quizila, nos terreiros de candomblé, é aquilo que é tabu.
}

\section{A produção da cerâmica popular baiana na atualidade}

Dentre as comunidades produtoras da cerâmica tradicional e popular baiana, podemos destacar algumas, de acordo com a predominância desta ou daquela influência. São elas: Maragogipinho, Irará, Coqueiros, Rio Real e Barra. Cabe ressaltar que não são estas as maiores, as únicas ou as mais importantes comunidades produtoras da nossa cerâmica, pois ela é também ricamente produzida em muitas outras 
comunidades em praticamente todo o nosso estado, como Jaguarari, Macaúbas, Nova Soure, Santo Antônio de Jesus, Ribeira do Amparo, Serrinha, Pilão Arcado e muito mais.

Distrito de Aratuípe, a Vila de Maragogipinho fica às margens do Rio Jaguaripe, e é considerado um dos maiores, senão o maior, polo produtor de cerâmica popular do país. A influência Ibérica está representada não só na variedade da decoração, cheia de arabescos e florais, mas também nos tornos com que são produzidas as peças nas formas de bilhas, cântaros, porrões, moringas, talhas e resfriadeiras. Na Vila de Maragogipinho são os homens que fazem a parte mais dura do trabalho (característica não só desta comunidade, mas de muitas outras no estado), eles são responsáveis pela colheita da matéria-prima, pelo preparo da massa (processo de amassagem da argila) e pelo levantamento das peças. Às mulheres, cabe a tarefa de brunir (brunimento: processo de esfregar a peça semi-seca com sementes, sabugo de milho, cacos ou seixos, conferindo brilho e polimento à superfície do objeto) e a decoração com pintura usando pinceis de pelo de gato.

Excetuando-se Rosalvo e João, irmãos santeiros cujas peças sofrem forte influência barroca e de um rebuscado rococó, são raros os exemplos de cerâmica figurativa em Maragogipinho. A ênfase é nas figuras zoomorfas (boi de bilha), antropomórficas (moringas com formato de baianas) e nas louças utilitárias, que, por sua vez, também estendem-se aos caxixis, que são as miniaturas destas louças, geralmente feitos por aprendizes, que não assumem pintura alguma (exceto o vidrado) e, além do uso decorativo, ajudam no processo de queima, como enchimento de forno.

Irará, vila rural às margens do Rio Paraguassú, possui uma cerâmica de forte influência indígena, incluindo ai algumas formas que se assemelham às antigas urnas funerárias usadas pelos índios, e negra, com grandes porrões utilizados para armazenar água.

Uma curiosidade da produção cerâmica são as cruzes que os homens, após coletar o barro nas serras e triturar com pilão, marcam nas bolas, ou moleques, com as quais retirarão os pedaços na hora de suspender as peças. Este sinal de cruz, produto de fé, é feito porque tudo com D'us ajuda.

A produção de Irará consiste em potes, tachos, panelas, caborés, porrões, caqueiros, fogareiros e etc, sempre bojudos (pela influência indígena) e de cor vermelho escura, vibrante. Esta cor vem da coloração com o tauá e do brunimento com seixos rolados e sabugo de milho. As peças são queimadas em fornos redondos, feitos de tijolos maciços e abertos no topo.

Em Coqueiros, também às margens do Rio Paraguaçu, localidade do município de Maragogipe, o ofício com a cerâmica é uma atividade feminina, já que os homens, exceto por alguns poucos que fabricam alguidares para torrar farinha, ocupam-se da pesca e do pequeno comércio.

Com uma produção constituída basicamente de panelas, travessas, alguidares, tachos, fogareiros e frigideiras diversos, e sua suspensão segue a técnica indígena do roletado, com pintura em tauá e brunimento com seixos rolados. Outra característica única de Coqueiros é que as ceramistas possuem outro lugar, separado da residência, 
para a confecção das peças; é a chamada casa do barro, geralmente de taipa (hoje em dia sendo substituídas pela alvenaria) e sem maiores confortos. Já o processo de queima, sim, é uma atividade comunitária, mais uma vez ai incide a influência indígena, com as peças sendo acomodadas numa fogueira ao ar livre, em forma de cone, com a observância e o domínio da fonte calorífica, como a direção do vento, altura das chamas e, especialmente, o momento exato de se mexer na fogueira e retirar as peças (quando se atinge a temperatura desejada).

São estas, as Cerâmicas de Coqueiros, as muito conhecidas (e preferidas pelos donos de restaurantes) louças que acompanham os pratos típicos da cozinha baiana.

Em Rio Real, cujo maior expoente são os diversos tipos de potes em alto relevo (infelizmente hoje em dia quase em extinção), produzem-se peças de forte influência ibérica (não só na forma, mas também na decoração, com motivos rendados na pintura) que vão de moringas de diversos tipos, as simples, as moringas galinha, as moringas cabaças com dois ou mais bojos até panelas e alguidares. Como na maioria das comunidades ceramistas, os homens são os responsáveis pela coleta da matéria-prima, e as mulheres as responsáveis por preparar a massa e suspender as peças, usando mais uma vez a técnica do roletado, o tauá e o brunimento com sementes de mucunã ou olho de boi. É uma cerâmica de decoração delicada, feita com o próprio barro dissolvido em água e aplicado com insope ${ }^{9}$. A queima é feita em fornos redondos, usando como combustível lenha e gravetos de candeia, camaçari e catinga de jacaré, demonstrando - outra vez - o domínio da combustão dos materiais.

A cerâmica produzida em Rio Real demanda uma particular atenção, pois vem sofrendo com a redução do número de artesãs e, cada vez mais, a dificuldade de ainda se conseguir barro de boa qualidade nos barreiros da região.

Finalizando este trabalho, a cerâmica de Barra é mais um exemplo da influência indígena e ibérica na nossa cultura popular. Lá se fazem potes, diversos tipos de moringas (moringas-moça, galinha, pato), santos, miniaturas e castiçais. 0 processo começa com a coleta da argila às margens do Rio São Francisco, depois a pilagem e amassagem do barro (trabalho realizado por rapazes) e, depois, o levantamento das peças - ai sim, já pelas mulheres - usando roletado e brunindo mais uma vez com seixos e sementes de mucunã.

A decoração varia. A peça pode ser pintada com tauá e decorada com tabatinga branca, ou o contrário, usando-se sempre chumaços de algodão amarrados numa talisca como pincel, com a queima feita mais uma vez comunitariamente, em fornos à lenha.

${ }^{10}$ Insope é um pincel feito com fiapos de tecido amarrados a um talinho de palmeira pindoba.

\section{Conclusão}

Todo o processo evolutivo da cerâmica popular baiana foi baseado numa sequência cumulativa de influências. Primeiro os indígenas, pré-coloniais, desenvolveram suas técnicas e aprimoraram o processo da queima e uso de diversos tipos de materiais, depois vieram os portugueses e sua influência ibérica, que nos trouxe um 
enriquecimento nas formas, na variedade, na construção e na decoração das peças; e, por último, mas não menos importante, os negros, que acrescentaram um tempero lúdico à coisa, estabelecendo uma relação barro + vida, tão bem sacramentada quanto nos tempos de Adão e Eva.

Esta cerâmica popular, hoje em dia alvo de intensas influências de design e decoração próprias do mundo industrializado - que nem sempre são positivas, pois geralmente interferem no método de produção e na forma estilística tradicional - não podem perder a sua essência, técnicas e características principais, sob pena de - assim - perdermos um pouco da nossa própria essência, do nosso próprio ser, enquanto também o resultado de um caldo de miscigenação e adaptação. Cabe não só aos governos e às pessoas, mas também à população acadêmica, o estudo e a preservação deste nosso bem maior, a nossa história.

\section{Referências}

SPENCER. Introduction à la science social - Chap III apud SIGHELE, Scipio. A multidão criminosa - ensaio de psicologia coletiva . Rio de Janeiro, eBooksBrasil, 2006, p. 11.

MACHADO, Clotilde de Carvalho. O Barro na Arte Popular Brasileira. Rio de Janeiro: 1977, p. 17

OTT, Carlos. Pré-História da Bahia. Salvador, Progresso, 1958, p. 37

Cerâmica Popular, Salvador, Instituto Mauá, 1994, p. 19

ETCHeVARNe, Carlos. Cerâmica Popular, Salvador: 1994. p. 31: Acerca das primeiras manifestações ceramistas da Bahia

ALMEIDA, Marlice. Cerâmica Popular, Salvador: 1994. p. 53: A obra realiza-se no momento da criação

Ensaio sobre a Feira dos Caxixis. Salvador: 2007

- Cerâmica Popular Baiana: Coqueiros, Irará e Rio Real. Apresentação para o Congresso Nacional de Técnicas para as Artes do Fogo, São Bernardo do Campo, 2008

Disponível na internet em http://pt.wiktionary.org/wiki/quizila - Acessado em 20/07/2012, às 19:55.

Disponível na internet em http://pt.wikipedia.org/wiki/Axex\%C3\%AA - Acessado em 20/07/2012, às 19:58.

Disponível na internet em http://pt.wikipedia.org/wiki/Vaso_can\%C3\%B3pico - Acessado em 20/07/2012, às 20:33.

Disponível na internet em http://pt.wikipedia.org/wiki/Ex\%C3\%A9rcito_de_terracota Acessado em 20/07/2012, às 20:40. 